\title{
Bovine neonatal pancytopenia - Comparative proteomic characterization of two BVD vaccines and the producer cell surface proteome (MDBK)
}

Kerstin N Euler ${ }^{1}$, Stefanie M Hauck ${ }^{2}$, Marius Ueffing ${ }^{2,3}$ and Cornelia A Deeg ${ }^{1^{*}}$

\begin{abstract}
Background: Bovine neonatal pancytopenia (BNP) is a disease syndrome in newborn calves of up to four weeks of age, first observed in southern Germany in 2006. By now, cases have been reported in several countries around the globe. Many affected calves die within days due to multiple haemorrhages, thrombocytopenia, leukocytopenia and bone marrow depletion. A certain vaccine directed against Bovine Virus Diarrhoea Virus (BVDV) was recently shown to be associated with BNP pathogenesis. Immunized cows develop alloantibodies that are transferred to newborn calves via colostrum intake. In order to further elucidate BNP pathogenesis, the purpose of this study was to characterize and compare the protein composition of the associated vaccine to another vaccine directed against BVDV not related to BNP and the cell surface proteome of MDBK (Madin-Darby Bovine Kidney) cells, the cell line used for production of the associated vaccine.
\end{abstract}

Results: By SDS-PAGE and mass spectrometry, we were able to detect several coagulation-related and immune modulatory proteins, as well as cellular and serum derived molecules being shared between the associated vaccine and MDBK cells. Furthermore, the number of proteins identified in the BNP related vaccine was almost as high as the number of surface proteins detected on MDBK cells and exceeded the amount of proteins identified in the non-BNP related vaccine over 3.5 fold. The great amount of shared cellular and serum derived proteins confirm that the BNP associated vaccine contained many molecules originating from MDBK cells and vaccine production.

Conclusions: The respective vaccine was not purified enough to prevent the development of alloantibodies. To narrow down possible candidate proteins, those most likely to represent a trigger for BNP pathogenesis are presented in this study, giving a fundament for further analysis in future research.

\section{Background}

Bovine neonatal pancytopenia (BNP) is a disease transferred by colostral alloantibodies binding to peripheral blood-derived leukocytes and platelet antigens of calves [1]. Remarkably, calves develop a severe thrombocytopenia and leukocytopenia within few hours after passive transfer of colostral antibodies to blood and die within several days from bleeding disorder and bone marrow depletion [1,2]. Respective alloantibodies responsible for BNP can develop in cows previously vaccinated with a specific Bovine Viral Diarrhoea (BVD) vaccine (PregSure BVD; Pfizer, Berlin, Germany; vaccine A) [1]. Colostra of these cows transfer

\footnotetext{
*Correspondence: Deeg@tiph.vetmed.uni-muenchen.de

'Institute of Animal Physiology, Department of Veterinary Sciences, LMU

Munich, Veterinärstr. 13, München D-80539, Germany

Full list of author information is available at the end of the article
}

BNP to healthy calves, indicating a commonly expressed target antigen in responding calves [2]. Alloantibodies are also detectable in blood of respective BNP dams [1], suggesting their development to be systemically and not directly in udder. Further immunological characterization of these antibodies revealed that they were of IgG1 subclass [3]. IgG1 antibodies reflect a Th2-response in cows. So far, Major histocompatibility complex class I (MHC I) was identified as one potential BNP alloantigen in two independent studies, one demonstrating alloimmune reactions to MDBK cell lysates of BNP donors [4] and the other describing responses to vaccine A derived proteins [5], but there are also other data indicating a different alloantigen [3]. Defects in coagulation of platelets, the decline of platelets and thus the low platelet count are the main cause for the multiple haemorrhages leading to the death of affected

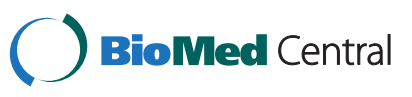

(C) 2013 Euler et al.; licensee BioMed Central Ltd. This is an Open Access article distributed under the terms of the Creative Commons Attribution License (http://creativecommons.org/licenses/by/2.0), which permits unrestricted use, distribution, and reproduction in any medium, provided the original work is properly cited. 
calves. However, the antigen(s) appear(s) to be also expressed on mature PBL as Assad et al. demonstrated binding of colostrum-derived antibodies to several PBL subsets and platelets [3], and further on hematopoietic progenitor cells of the myeloid and lymphoid lineages in the bone marrow, as these are, according to Laming et al., comprised already 24 hours after colostrum intake and show a drastic decline within the first 6 days after colostrum intake [6].

BNP dams clearly develop alloreactive responses after vaccination with vaccine $A$, but not with other $B V D$ vaccines $[7,8]$. Immunization of experimental calves and guinea pigs with this vaccine led to generation of alloantibodies [9], which were also cross-reactive with MDBK cells [10], the cell line used for production of vaccine A [9]. MDBK line was derived from the renal tissue of an adult steer in 1957 [10]. MDBK cells are susceptible to infection with BVDV and a number of other viruses, including vesicular stomatitis virus, infectious bovine rhinotracheitis virus, bovine parvovirus, bovine adenovirus I and III, and parainfluenza virus 3 [11]. MDBK cells exhibit resistance to poliovirus 2 and are negative for reverse transcriptase.

Therefore, the goal of this study was to characterize and compare protein expression of MDBK cells, BNP associated vaccine $A$, and - as negative control to contrast the BVD virus associated constituents - a live-attenuated BVD vaccine unrelated to BNP (Vacoviron FS; Merial, Hallbergmoos, Germany; vaccine B) by label free mass spectrometry. The results may improve our understanding of differences in vaccine composition that could account for alloantibody formation in BNP dams.

\section{Results}

BNP associated BVD vaccine contains a variety of different proteins

First evaluation of protein composition of different BVD vaccines showed a clear difference between vaccine $B$ (Figure 1B) and A (Figure 1C). Vaccine A, related to BNP, included many different proteins in comparison to vaccine B which is not associated with BNP. Quantitative staining with colloidal Coomassie demonstrated a remarkable difference in protein concentration of vaccine A compared to vaccine $B$. In addition, silver staining confirmed little protein content in vaccine $B$ (Figure $1 B$ ) whereas vaccine A (Figure 1C) resembled the composition of MDBK cell proteome (Figure 1D).

We therefore decided to identify all proteins of respective samples with LC-MS/MS to categorize duplicate proteins in vaccine $\mathrm{A}$ and MDBK cells.

Mass spectrometric classification of protein content confirms large overlap between MDBK and PregSure BVD proteomes A total of 310 proteins were identified by LC-MS/MS in this study (see Additional file 1). 43 proteins were identified

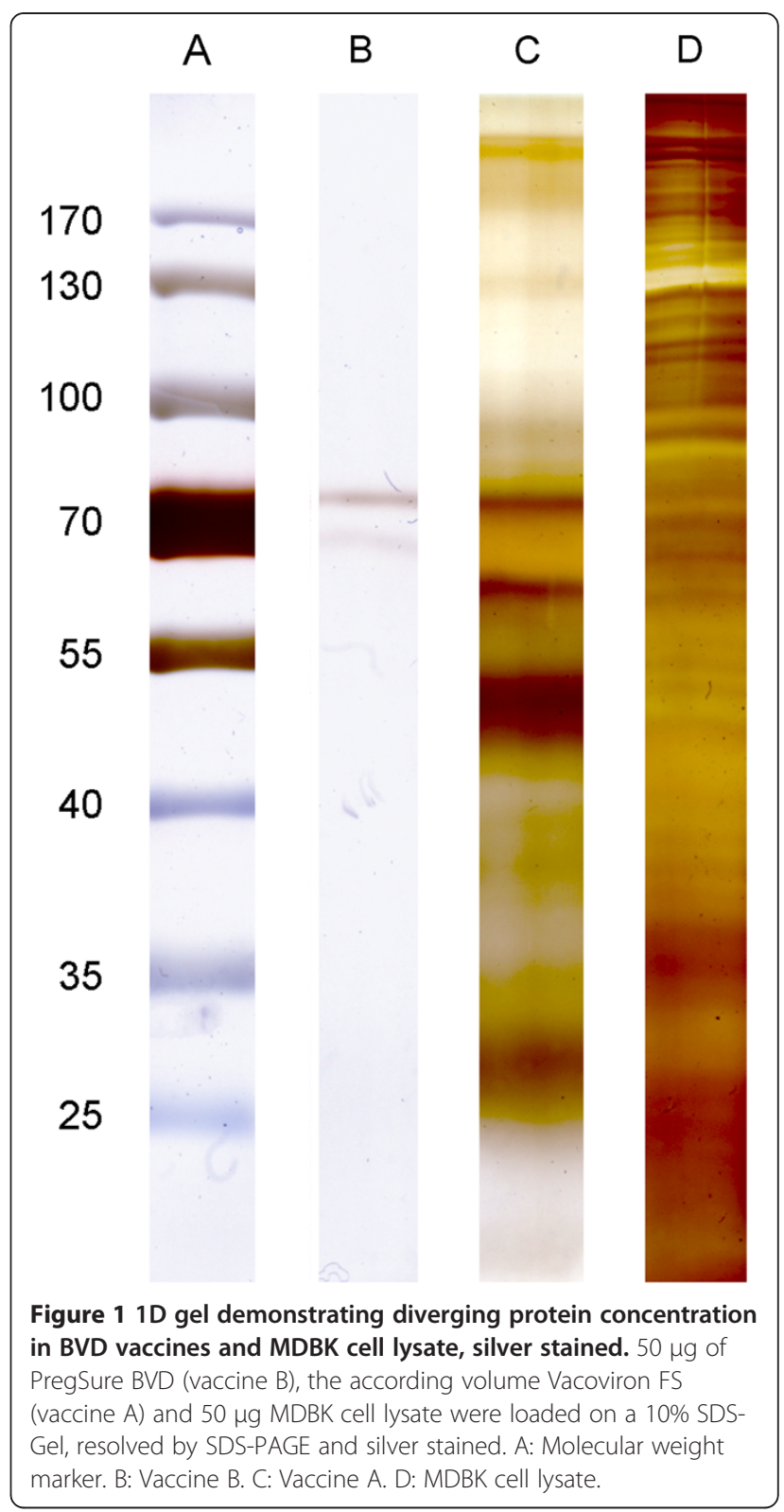

with two or more peptides in vaccine $\mathrm{B}$, a live-attenuated vaccine which is not related to BNP. In contrast, 159 proteins were detectable in vaccine A (vaccination with this vaccine strongly correlates with BNP occurrence) and 163 proteins on MDBK cell surface of which $66 \%$ are allocated to the Gene ontology (GO) project terms "plasma membrane", "cell surface" or "extracellular". There was an overlap of eight proteins in all three samples analyzed. Eleven proteins were present only in both vaccines $A$ and $B$, but not on MDBK cells. Three other proteins, alpha-S1-casein, kappa-casein and keratin-5 appeared concurrently in vaccine $B$ and MDBK cells. Two BVD virus polyprotein peptides were detected in both vaccines (vaccine A: EMBL Database Accession Number: ABP57735.1; EMBL 
Database (http://www.ebi.ac.uk/embl/; vaccine B: EMBL Database Accession Number AAC61755.1).

Between vaccine A and MDBK cells, we detected 25 shared proteins (Tables 1 and 2). Among these were 17 proteins representing cellular components (Table 1, proteins $1-12,14,15,17,18$ and 25), e.g. histone H2B type 1 and mitochondrial proteins ATP synthase subunits alpha, beta and adenylate kinase 2 (AK 2). Further, we detected ribosomal proteins S3, S4 and L7a and representatives of cytoplasmatic protein fraction. The latter were structural proteins of the cytoskeleton, such as actin, or proteins in charge of energy balance like glyceraldehyde-3-phosphate

\section{Table 1 Shared proteins between vaccine $A$ and MDBK} cell surface

\begin{tabular}{|c|c|c|c|}
\hline No. & Identified Protein & Accession Number & $\begin{array}{c}\mathrm{MW} \\
(\mathrm{kDa})\end{array}$ \\
\hline 1 & Histone H2B type 1 & ENSBTAP00000024155 & 25 \\
\hline 2 & $40 \mathrm{~S}$ ribosomal protein $\mathrm{S} 3$ & ENSBTAP00000003962 & 27 \\
\hline 3 & $40 S$ ribosomal protein $\$ 4$ & ENSBTAP00000052226 & 30 \\
\hline 4 & $60 S$ ribosomal protein $\mathrm{L7a}$ & ENSBTAP00000015358 & 30 \\
\hline 5 & $\begin{array}{l}\text { Actin, cytoplasmic 2, N-terminally } \\
\text { processed }\end{array}$ & ENSBTAP00000008132 & 42 \\
\hline 6 & Alpha-actinin-4 & ENSBTAP00000014894 & 105 \\
\hline 7 & Keratin 8 & ENSBTAP00000001108 & 54 \\
\hline 8 & $\begin{array}{l}\text { Glyceraldehyde-3-phosphate } \\
\text { dehydrogenase }\end{array}$ & ENSBTAP00000037577 & 36 \\
\hline 9 & Alpha-enolase & ENSBTAP00000017839 & 47 \\
\hline 10 & Pyruvate kinase & ENSBTAP00000044619 & 61 \\
\hline 11 & Endopin-2 & ENSBTAP00000011576 & 47 \\
\hline 12 & $\begin{array}{l}\text { Sodium/potassium-transporting } \\
\text { ATPase subunit alpha-1 }\end{array}$ & ENSBTAP00000001646 & 113 \\
\hline 13 & Alpha-2-HS-glycoprotein & ENSBTAP00000000673 & 38 \\
\hline 14 & MHC class I heavy chain isoform 1 & ENSBTAP00000031126 & 40 \\
\hline 15 & $\begin{array}{l}\text { Heat shock cognate } 70 \mathrm{kDa} \\
\text { protein } 8\end{array}$ & ENSBTAP00000017497 & 71 \\
\hline 16 & Hemopexin & ENSBTAP00000004635 & 52 \\
\hline 17 & $\begin{array}{l}\text { ATP synthase subunit alpha, } \\
\text { mitochondrial }\end{array}$ & ENSBTAP00000003259 & 60 \\
\hline 18 & $\begin{array}{l}\text { ATP synthase subunit beta, } \\
\text { mitochondrial }\end{array}$ & ENSBTAP00000017710 & 56 \\
\hline 19 & Complement C3 & ENSBTAP00000022979 & 187 \\
\hline 20 & Complement C4 & ENSBTAP00000009019 & 102 \\
\hline 21 & Vitamin D-binding protein & ENSBTAP00000033386 & 53 \\
\hline 22 & Thrombospondin-1 & ENSBTAP00000002600 & 129 \\
\hline 23 & Alpha-1-acid-glycoprotein & ENSBTAP00000022991 & 23 \\
\hline 24 & Alpha-1-antiproteinase & ENSBTAP00000004927 & 46 \\
\hline 25 & Adenylate kinase 2, mitochondrial & ENSBTAP00000023406 & 26 \\
\hline
\end{tabular}

25 proteins could be co-identified in vaccine $A$ and on MDBK cells. Proteins listed were identified by LC-MS/MS with a probability score that is significant with $p<0.05$ if the confidence score was $>30$ at a significance threshold for the Mascot result of $p \leq 0.01$. Accession number as listed on Ensembl database (http://www.ensembl.org). dehydrogenase (GAPDH). Also, the chaperone heat shock cognate $70 \mathrm{kDa}$ protein 8 (hsc70) and an inhibitor of cysteine and serine proteases, endopin-2 [12] belong to this fraction. Besides, two membrane-bound proteins, namely sodium/potassium-transporting ATPase subunit alpha-1, essential for osmoregulation [13], and MHC I heavy chain isoform 1, which is expressed on all mammalian nucleated cells [14], were identified (Table 1, proteins 12 and 14).

Further, eight serum-derived proteins were detected (Table 1, proteins 13, 16 and 19-24). Complement 3 (C3) and $\mathrm{C} 4$ are abundant blood components and members of complement cascade [15]. Alpha-2-HS-glycoprotein, vitamin D-binding protein (VDBP), alpha-1-acid-glycoprotein, and hemopexin represent important transport proteins [16-19], alpha-1-antiproteinase participates in woundhealing [20] and thrombospondin-1 (TSP-1) is associated with platelet aggregation [21]. The protein percentage of total spectra, the number of unique peptides of the proteins identified, the number of total spectra identified for respective proteins and the percentage of amino acids identified in vaccine A are presented in Table 2. According to these parameters, the most abundant of the proteins detected concurrently in vaccine A and on MDBK cell surface was C4 (Table 2, protein 1), while $60 \mathrm{~S}$ ribosomal protein L7a and MHC class I heavy chain (Table 2, proteins 24 and 25) were the least abundant.

\section{Discussion}

For the first time, we characterized the proteome of two BVD vaccines and compared their protein content and concentration in regard to BNP pathogenesis. The inactivated BVD vaccine $A$ contained over 3.5 fold more proteins than the live-attenuated vaccine $B$ and still over twice as many compared to a meningococcal vaccine, where 47 proteins were identified by similar proteomic approaches [22]. Total protein quantity of vaccine A and MDBK cells was almost equal, underlining our findings that the protein content of vaccine $\mathrm{A}$ and the host cell line surface resemble each other (Figure $1 \mathrm{C}$ and $\mathrm{D}$ ). This indicates that the vaccine antigens have not or only insufficiently been purified. Further, the number of individual proteins was much lower in vaccine $B$ compared to vaccine $\mathrm{A}$, which was expected of the live-attenuated vaccine $B$ and the reason why it was used as a qualitative negative control. Also, the protein concentrations of both vaccines differed greatly. Thus, the administered amount of protein in vaccine $\mathrm{A}$ exceeds the one applied when immunizing with vaccine $B$ according to dosage instructions.

Furthermore, we provided proteomic characterization of MDBK cell surface. $66 \%$ of identified proteins on MDBK cells were attributed with the Gene Ontology project terms "plasma membrane", "cell surface" or "extracellular", indicating a high enrichment of proteins already known to be allocated to the plasma membrane. Although this 
Table 2 Abundance of proteins in vaccine A shared with MDBK

\begin{tabular}{|c|c|c|c|c|c|c|c|}
\hline No. & Identified Protein & Accession Number & $\begin{array}{c}\text { MW } \\
(\mathrm{kDa})\end{array}$ & $\begin{array}{c}\text { total spectra } \\
(\%)\end{array}$ & $\begin{array}{l}\text { unique peptide } \\
\text { count }\end{array}$ & $\begin{array}{l}\text { total spectra } \\
\text { count }\end{array}$ & $\begin{array}{c}\text { Coverage } \\
(\%)\end{array}$ \\
\hline 1 & Complement C4 & ENSBTAP00000009019 & 102 & 0.150 & 36 & 81 & 30.0 \\
\hline 2 & $\begin{array}{l}\text { Actin, cytoplasmic 2, N-terminally } \\
\text { processed }\end{array}$ & ENSBTAP00000008132 & 42 & 0.120 & 10 & 64 & 45.0 \\
\hline 3 & Pyruvate kinase & ENSBTAP00000044619 & 61 & 0.066 & 17 & 35 & 40.0 \\
\hline 4 & keratin, type II cytoskeletal 8 & ENSBTAP00000001108 & 54 & 0.057 & 13 & 30 & 31.0 \\
\hline 5 & Histone H2B type 1 & ENSBTAP00000024155 & 25 & 0.055 & 4 & 29 & 35.0 \\
\hline 6 & Thrombospondin-1 & ENSBTAP00000002600 & 129 & 0.043 & 15 & 23 & 17.0 \\
\hline 7 & $\begin{array}{l}\text { Glyceraldehyde-3-phosphate } \\
\text { dehydrogenase }\end{array}$ & ENSBTAP00000037577 & 36 & 0.038 & 8 & 20 & 37.0 \\
\hline 8 & Alpha-1-antiproteinase & ENSBTAP00000004927 & 46 & 0.032 & 2 & 17 & 7.2 \\
\hline 9 & Heat shock cognate $70 \mathrm{kDa}$ protein 8 & ENSBTAP00000017497 & 71 & 0.032 & 12 & 17 & 29.0 \\
\hline 10 & $\begin{array}{l}\text { ATP synthase subunit beta, } \\
\text { mitochondrial }\end{array}$ & ENSBTAP00000017710 & 56 & 0.028 & 9 & 15 & 25.0 \\
\hline 11 & Alpha-actinin-4 & ENSBTAP00000014894 & 105 & 0.026 & 11 & 14 & 19.0 \\
\hline 12 & Alpha-1-acid glycoprotein & ENSBTAP00000022991 & 23 & 0.021 & 5 & 11 & 31.0 \\
\hline 13 & Vitamin D-binding protein & ENSBTAP00000033386 & 53 & 0.019 & 2 & 10 & 7.0 \\
\hline 14 & Adenylate kinase 2, mitochondrial & ENSBTAP00000023406 & 26 & 0.017 & 7 & 9 & 42.0 \\
\hline 15 & $40 S$ ribosomal protein $\mathrm{S} 3$ & ENSBTAP00000003962 & 27 & 0.013 & 3 & 7 & 15.0 \\
\hline 16 & Alpha-enolase & ENSBTAP00000017839 & 47 & 0.013 & 5 & 7 & 18.0 \\
\hline 17 & $\begin{array}{l}\text { ATP synthase subunit alpha, } \\
\text { mitochondrial }\end{array}$ & ENSBTAP00000010806 & 60 & 0.011 & 4 & 6 & 12.0 \\
\hline 18 & Endopin 2 & ENSBTAP00000011576 & 47 & 0.009 & 3 & 5 & 13.0 \\
\hline 19 & Hemopexin & ENSBTAP00000004635 & 52 & 0.009 & 3 & 5 & 12.0 \\
\hline 20 & Alpha-2-HS-glycoprotein & ENSBTAP00000000673 & 38 & 0.008 & 3 & 4 & 17.0 \\
\hline 21 & $\begin{array}{l}\mathrm{Na}^{+} / \mathrm{K}^{+} \text {-transporting ATPase subunit } \\
\text { alpha-1 }\end{array}$ & ENSBTAP00000001646 & 113 & 0.008 & 3 & 4 & 3.3 \\
\hline 22 & $40 S$ ribosomal protein 54 & ENSBTAP00000052226 & 30 & 0.006 & 3 & 3 & 12.0 \\
\hline 23 & Complement C3 & ENSBTAP00000022979 & 187 & 0.006 & 3 & 3 & 4.9 \\
\hline 24 & 605 ribosomal protein L7a & ENSBTAP00000015358 & 30 & 0.004 & 2 & 2 & 13.0 \\
\hline 25 & MHC class I heavy chain isoform 1 & ENSBTAP00000031126 & 40 & 0.004 & 2 & 2 & 6.4 \\
\hline
\end{tabular}

Proteins identified concurrently in vaccine A and on MDBK cell surface by LC-MS/MS are shown in the order of the protein percentage of total spectra, reflecting their abundance in vaccine A, from lowest to highest concentration. Accession number as listed on Ensembl database (http://www.ensembl.org). Proteins listed were identified with a probability score that is significant with $p<0.05$ if the confidence score was $>30$ at a significance threshold for the Mascot result of $p \leq$ 0.01. total spectra (\%): percentage of total spectra assigned to respective protein. unique peptide count: number of unique peptides for the identified protein. total spectra: number of total spectra assigned to the identified protein. coverage (\%): percentage of total amino acid sequence covered with the identified peptides.

certainly reflects technical limitations that are inherent in most membrane-associated fraction enrichment methods, as one third of these identified proteins are currently not attributed as cell surface proteins, it could on the other hand also point out that several proteins might be additionally expressed on the cell surface, but that their presence on this location has not yet been described. One prominent example is ATP Synthase, an ubiquitous protein of the oxidative phosphorylation pathway which was considered to be an exclusively mitochondrial protein for decades, but was discovered recently on the cell surface of a great variety of cell types [23]. MDBK cells are often used as culture system for growing attenuated viruses in vaccine production [24], e.g. BVDV [9]. Proteins detected in all preparations or overlapping in one vaccine and MDBK cells indicate an impurity of the vaccines with homologous proteins due to manufacturing processes. Proteins present in both vaccines suggest a vaccine specific role, possibly as adjuvants. Calreticulin, for instance, which was detected in both vaccines, aids in antigen presentation promoting antigen contact to MHC I [25]. This immune enhancing property constitutes its use as compound of vaccines, especially tumor vaccines [25].

By characterizing the host cell line used in manufacturing vaccine $A$, vaccine $A$ itself and the qualitative negative control vaccine $B$ proteomically, we were able to narrow 
down proteins administered through vaccine A to several interesting candidates which might be involved in pathogenesis of BNP. Here we discuss proteins that we believe deserve further evaluation because they offer interesting properties such as an association with clotting, being previously reported to be involved in immune diseases that show symptoms similar to the ones seen in BNP or a location on cell types affected in BNP pathogenesis. The rapid decrease in the number of platelets and leukocytes in the circulating blood within the first few hours after colostrum intake is most likely directly antibody-mediated and probably not due to bone marrow depletion. Whereas the haematopoietic progenitor cells are compromised in their ability to form colonies as early as 24 hours after uptake of colostral antibodies, the decrease of haematopoietic progenitor cells develops over a longer period of time [6]. Thus, we suspect the antigen or antigens to be located on PBL, platelets and, in regard to the bone marrow depletion, also on haematopoietic progenitor cells of the myeloid and lymphoid lineages.

Interestingly, Pfizer used a new potent adjuvant in vaccine A, containing immunostimulating complexes. These structures envelop the antigen enhancing its uptake into immune-modulatory cells [26]. The saponin mixture Quil A is part of these complexes. Its use in human vaccines was restricted based on its high toxicity and haemolytic effect [27], until introduction of respective complexes reduced these effects [28]. Further, the adjuvant also contains drakeol 5, a regular mineral oil, which is often used in veterinary vaccine production and helps stabilize the emulsion of vaccine components. Since it cannot be metabolized, it maintains a slow release of antigen and remains in the injected tissue as an oil pool or depot. It is also known to lead to a prolonged irritation at the injection site, thus reflecting the possible side effects of the vaccine according to the instruction leaflet [29].

The adjuvant is believed to have potentiated reactions to alloantigens present in vaccine A [9]. To avoid a false negative selection of our candidate proteins, we chose a liveattenuated vaccine as negative control. On the one hand, these vaccines generally contain less protein than inactivated vaccines. Acquiring another BVD vaccine with a high protein variety, as other inactivated vaccines predictably would show, would have beared the risk of ruling out valuable candidate proteins that might only lead to antibody production due to the effect of the new adjuvant used in vaccine $\mathrm{A}$. On the other hand, a live-attenuated vaccine more likely provides proteins that are only present due to certain technical limitations of manufacturing processes in vaccine production.

Pfizer withdrew the registration of vaccine A in Europe in June 2010 (in Germany even two months earlier, in April 2010). It took another 14 months until vaccine A was drawn from the market in New Zealand in
August 2011, right after the first case was reported there. It is worth mentioning that there is a close correlation of the time period when vaccine $\mathrm{A}$ was brought to market in Europe in 2004, with cases of haemorrhagic diatheses occurring cumulatively in 2007, and it being available for vaccination in New Zealand in May 2008 where also, three years later, the first diagnosed case of BNP occurred in August 2011.

Analysing the MDBK cell surface proteome (see Additional file 1), we detected several interesting BNP alloantigen candidates, such as integrin alpha-IIB (CD41) and von Willebrand factor, that have essential functions in clotting $[30,31]$. Although they did not appear in vaccine A, we hypothesized that, since the oily formulation of the vaccine made it difficult to handle it technically [5], the antigen might have been undetectable by LC-MS/MS. Thus, we tried to validate CD41 in vaccine A by Western blot analysis with an antibody directed against human CD41 protein (data not shown) since this was the only available commercial antibody at this point of time, but did not succeed in verifying our hypothesis.

Proteins identified in vaccine $\mathrm{A}$ and MDBK cells (Tables 1 and 2) demonstrate a clear difference in composition of vaccine A and B. This group most likely contains candidate proteins capable of triggering production of alloantibodies in BNP pathogenesis.

Several of these proteins are common cellular components (Table 1, proteins 1-12, 14, 15, 17, 18 and 25). For instance, GAPDH contributes to cellular energy supply and is considered a housekeeping protein [32]. Occurrence of these MDBK cell associated proteins in vaccine A (and lack of these in vaccine B) confirm high amount of cellular debris in vaccine A.

Previous studies described vaccine A being contaminated with MHC I, which was also present on MDBK cells and supposedly induced alloreactive antibodies in BNP dams $[4,5]$. Although we detected MHC I in both preparations (Table 1, protein 14 and Table 2, protein 25), we do not support the hypothesis that MHC I alloantibodies cause BNP pathogenesis. We could show by immunological characterization that BNP alloantibodies have another binding pattern than MHC I expression [3]. There was a difference in alloantibody binding to different lymphocyte subsets whereas MHC I is evenly expressed on all lymphocytes [14]. Also, MHC I was the least abundant protein according to the protein percentage of spectral counts in our LC-MS/MS results (Table 2, protein 25). Further, human MHC I (HLA I) alloantibodies contribute to transfusion-related acute lung injury (TRALI), a frequent complication in transfusion medicine [33]. Affected patients develop acute lung edema within six hours of transfusion, caused by administration of a great amount of antibodies from donor blood directly into the recipient's circulation. This contrasts to BNP, where calves suffer 
fatal bleeding up to four weeks after colostrum intake. Although MHC I antibodies were the most frequent alloantibodies $(73 \%)$ detected in TRALI, they were only weak triggers and did not cause any fatal case [34]. Still, not all important transfusion alloantigens are detected for humans. This was recently shown by Greinacher et al. who identified a biallelic polymorphism in human neutrophile antigen 3a (HNA-3a) as alloantigen in TRALI, resulting from a single-nucleotide exchange in the choline transporter-like protein [33]. HNA-3a is a more potent alloantigen causing a more severe and fatal course of TRALI. Identification of this alloantigen was technically challenging and covered by prominent anti MHC I immune reaction of respective patients. This could also be the case in BNP, therefore investigation of involved alloantigens continues until pathogenesis induction is proven by a monospecific antibody.

Interestingly, we identified several proteins that were previously described as targets in auto- or alloimmunemediated diseases. Alpha-enolase (Table 1, protein 9 and Table 2, protein 16), a glycolytic enzyme and plasminogenbinding protein on leukocytes [35], is an autoantigen in rheumatoid arthritis [36] and Behcet's disease [37]. Hsc70 (Table 1, protein 15 and Table 2, protein 9) acts as chaperone of proteins to other chaperones or membranes and takes part in cellular thermo tolerance [38]. Antibodies against heat shock proteins were detectable in many autoimmune diseases, e.g. myasthenia gravis [39]. ATP synthase (Table 1, proteins 17 and 18 and Table 2, proteins 10 and 17) catalyzes ATP from ADP at the mitochondrial membrane and is present on surface of various cells, including endothelial cells, where it is an autoantigen in immunemediated vasculitides [40]. Although C3 and C4 (Table 1, proteins 19 and 20 and Table 2, proteins 1 and 23) play a significant role in the innate immune system [15] a mouse model demonstrated that deficiency in C3 can be compensated by thrombin [41] and a genetically determined deficiency of $\mathrm{C} 4$ increases the risk for developing systemic lupus erythematosus [42]. Alloantibodies directed against this group of proteins, however, seem unlikely to be involved in BNP pathogenesis as their functions and the immunemediated diseases do not correlate with bleeding disorders.

In addition, we were able to detect candidate proteins directly affecting cell types reported as BNP targets, namely platelets, monocytes, granulocytes, B- and T-cells [3].

Vitamin D binding protein (Table 1, protein 21 and Table 2, protein 13) acts as transport protein for vitamin $\mathrm{D}$ in plasma, and is present on human neutrophils, B-cells and a subset of T-cells, enhancing C5a chemotaxis of macrophages and neutrophils [43]. Alloantibodies against these cells could explain several symptoms of BNP, e.g. lymphocytopenia and neutropenia [1].

A further interesting BNP alloantigen candidate was thrombospondin-1 (TSP-1; Table 1, protein 22 and Table 2, protein 6), a protein secreted by and bound on surface of various cells including endothelial cells, monocytes, macrophages, and platelets [44]. It is an important interactor of coagulation proteins such as fibrinogen, fibrin, integrins and neutrophil elastase. It activates leukocytes, inhibits T-cell effectors and directly induces T-cell apoptosis [44]. Further, it promotes T-cell adhesion and chemotaxis [44]. TSP-1 null mice showed increased bleeding and colonic inflammation in acute induced colitis compared to controls [44]. Therefore, TSP-1 merits further exploration as possible $\mathrm{BNP}$ alloantigen.

Alpha-1-acid-glycoprotein (Table 1, protein 23 and Table 2, protein 12) was detected, a plasma protein with many immune-modulatory functions, e.g. expression of anti-inflammatory cytokines by macrophages, decreasing chemotaxis of neutrophils and inhibiting proliferation of lymphocytes [19]. It is also synthesized during granulocyte differentiation and stored in granules, but can further be produced at inflammation sites, e.g. by endothelial cells and activated macrophages, or transported to affected tissues by defensive cells, for instance neutrophils [19]. This protein has several functions in BNP pathogenesis associated pathways, therefore, alloantibodies against alpha-1acid-glycoprotein might potentially play an important role in development of BNP.

An additional interesting candidate was alpha-1antiproteinase (Table 1, protein 24 and Table 2, protein 8). It plays an important role in wound-healing [20], inhibiting plasmin and activating plasminogen and thrombin, and also inhibits haematopoietic stem cell mobilization in bone marrow [45]. Further, in vitro studies showed an increase of lipopolysaccharide-mediated macrophage activation and anti-inflammatory effects on B-cells, demonstrating an additional role in immune regulation [46]. Whereas inactivating mutations and deficiencies of alpha1 -antiproteinase only resulted in elastase-induced tissue damage, such as skin hyperextensibility [47], chronic obstructive pulmonary disease and liver disease [46] in humans, but not in bleeding disorders, the Pittsburgh mutation of alpha-1-antiproteinase results in a fatal haemorrhagic diathesis due to greatly enhanced proteaseinhibitory effects on thrombin, thus blocking the coagulation cascade [46]. These functions of alpha-1-antiproteinase make it an interesting BNP alloantigen candidate. We will therefore further examine an involvement of anti-alpha-1 -antiproteinase immune reactions in BNP pathogenesis.

Additionally, we identified adenylate kinase 2 (AK 2; Table 1, protein 25 and Table 2, protein 14) in vaccine A and MDBK cells. AK 2 is present in platelets, CD14 ${ }^{+}$, $\mathrm{CD} 9^{+}, \mathrm{CD}^{+}, \mathrm{CD}^{+} 6^{+}, \mathrm{CD} 6 \mathrm{~b}^{+}$cells and in mononuclear cells obtained from bone marrow [48]. AK 2 mutations cause reticular dysgenesis, the most severe combined immunodeficiency in humans [48]. In reticular dysgenesis, mononuclear cells decrease in bone marrow, thus blocking 
myeloid differentiation at promyelotic stage [48]. It induces similar aberrations in the haemogram and bone marrow as described for BNP [2], resulting in monocytopenia, neutropenia, and lymphopenia combined with normal erythrocyte count and thrombocytopenia in some cases [49]. AK 2 knock-down in zebrafish caused similar alterations in leukocyte development, emphasizing the high level of conservation of AK 2 in different species [48]. Further, loss of AK 2 does neither interfere with development of immature hematopoietic cells nor erythropoiesis, but with lymphocyte development which in this case cannot be compensated by AK 1 due to lower or absent expression in respective cell types [48]. Affected cell subsets, the association to bone marrow and alterations in haemogram closely resemble alterations seen in BNP [2]. Thus, we consider AK 2 the most promising candidate in this study. However, further investigations have to aim at validating its role in BNP pathogenesis.

\section{Conclusions}

We provide the first characterization of MDBK cell surface proteome and the proteomes of two BVD vaccines. BNP associated BVD vaccine A contained 159 proteins in comparison to BVD vaccine B (43 proteins, not BNPrelated). The great overlap of cellular and serum-derived components confirmed contamination of the BNP related vaccine A with proteins from MDBK cell line used for vaccine production. Several interesting BNP candidate alloantigens could be detected within the overlap of proteins present in BNP related vaccine A and on MDBK cell surface. VDBP, TSP-1, alpha-1-acid-glycoprotein, alpha-1antiproteinase, and AK 2 associate with coagulation and show a distribution resembling the affected tissues and cell populations in BNP. Alloantibodies against these proteins could play an important role in BNP pathogenesis and alloimmune reactions need to be further analyzed in future studies.

\section{Methods}

\section{Sample preparation}

MDBK cells (kindly provided by Falko Steinbach, Veterinary Laboratories Agency - Weybridge New Haw, Addlestone, Great Britain) were cultivated in RPMI-1640 medium supplemented with $10 \%$ heat-inactivated fetal calf serum (FCS) and $1 \%$ penicillin/streptomycin. Cells were maintained at $37^{\circ} \mathrm{C}$ and $5 \% \mathrm{CO}_{2}$. For protein expression analysis by mass spectrometry, cells were harvested with Trypsin/ EDTA (Biochrom, Berlin, Germany), washed twice with cold phosphate buffered saline, and centrifuged between washing steps at $4^{\circ} \mathrm{C}, 500 \times \mathrm{g}$ for 10 minutes $(\mathrm{min})$. Prior to cell lysis, plasma membrane proteins of $2 \times 10^{6}$ cells were labelled with $77.4 \mu \mathrm{g}$ biotin. After $30 \mathrm{~min}$ rotation at $4^{\circ} \mathrm{C}$ and two centrifugation steps at $2800 \times \mathrm{g}$ and $16000 \times$ $\mathrm{g}$ for 10 min each at $4^{\circ} \mathrm{C}$, cells were lysed with $1 \%$ Nonidet
P-40, $150 \mathrm{mM} \mathrm{NaCl}, 1 \times$ Roche Complete Protease Inhibitor, EDTA-free; $5 \mathrm{mM}$ 2-Iodacetamide in $10 \mathrm{mM}$ Tris- $\mathrm{HCl} \mathrm{pH} 7.6$ and biotinylated cell surface proteins were captured using Streptavidin-beads (IBA, Goettingen, Germany). After extensive washing to remove unspecifically bound proteins, captured proteins were cleaved through digesting beads overnight with trypsin (Promega, Mannheim, Germany) followed by incubation with glycerolfree PNGase F (New England Biolabs, Frankfurt/Main, Germany) at $37^{\circ} \mathrm{C}$. Peptides were purified and concentrated using Pierce PepClean C18 spin columns (Thermo Fisher Scientific, Bonn, Germany) according to manufacturer's protocol and subjected to analysis by liquidchromatography mass spectrometry/mass spectrometry (LC-MS/MS).

\section{SDS-PAGE}

After overnight precipitation of proteins from vaccine A with acetone at $-20^{\circ} \mathrm{C}$, the resulting pellet was resolubilized and both vaccines were resolved by $12 \%$ SDS-PAGE (sodium dodecyl sulfate polyacrylamide gel), followed by staining with Coomassie Brilliant Blue. After proteolysis with trypsin, samples were subjected to analysis by LCMS/MS.

MDBK cells were solubilized with lysis buffer ( $9 \mathrm{M}$ urea, $2 \mathrm{M}$ thiourea, 1\% DTT, 4\% CHAPS, and $2.5 \mathrm{mM}$ each of EGTA and EDTA) and protein content of both vaccines and the cell lysate was quantified with Bradford assay (Sigma-Aldrich, Deisenhofen, Germany).

Vaccine proteins and MDBK cell proteins were resolved by $10 \%$ SDS-PAGE, applying PageRuler Prestained Protein Ladder (Thermo Fisher) as reference marker. Gels were stained with silver and colloidal Coomassie [50] for a first comparison of protein content in vaccine A (related to BNP alloantibody generation [5]), vaccine B (unrelated to BNP alloantibody production) and MDBK cells.

\section{Mass spectrometry}

LC-MS/MS analysis was performed as described before [51,52]. Briefly, peptides were separated on a reversed phase chromatography column (PepMap, $15 \mathrm{~cm} \mathrm{x} 75 \mu \mathrm{m}$ ID, $3 \mu \mathrm{m} / 100 \mathrm{~A}$ pore size, LC Packings) operated on a nano-HPLC apparatus (Ultimate 3000, Dionex, Idstein, Germany). The nano-HPLC was connected to a linear quadrupole ion trap-Orbitrap (LTQ Orbitrap XL) mass spectrometer (Thermo Fisher). The mass spectrometer was operated in the data-dependent mode to automatically switch between Orbitrap-MS and LTQ-MS/MS acquisition. Survey full scan MS spectra (from m/z 300 to 1500) were acquired in the Orbitrap resolution $R=60,000$ at $\mathrm{m} / \mathrm{z} 400$. Up to ten most intense ions were in parallel selected for fragmentation on the linear ion trap using collision induced dissociation at a target value of 100,000 ions and subsequently dynamically excluded for $30 \mathrm{~s}$. 
MS/MS spectra were exported from the Progenesis software as Mascot Generic file (mgf) and used for peptide identification using Mascot (Matrix Science, London, UK; http://www.matrixscience.com), the Uniprot database (http://www.uniprot.org) restricted to mammalian entries, the Ensembl bovine database (http://www.ensembl.org) in particular, and the EMBL-Bank (http://www.ebi.ac.uk/ $\mathrm{embl} /$ ) for nucleotide sequences. A protein was considered as identified, if the confidence score was higher than 30 at a significance threshold for the Mascot result of $\mathrm{p} \leq 0.01$.

\section{Gene ontology project term classification of MDBK cell surface proteins}

Proteins identified on MDBK cell surface by LC-MS/MS were used for annotation of GO terms "cellular component". GO terms were retrieved from the Ensembl database and AmiGO (AmiGO version 1.8; GO database release 2012-12-08; http://amigo.geneontology.org), either directly from the entries in the bovine database or by searching orthologes in human, mouse or rat.

\section{Additional file}

Additional file 1: Summary of proteins identified in vaccine $A$, vaccine $B$ and on MDBK cell surface In total, 310 proteins were identified in vaccine $A$, vaccine $B$ and on MDBK cell surface. $A$ : Number of protein in list order. B: Protein name. C: Accession number as listed on Ensembl database (http://www.ensembl.org) or in EMBL Database (http://www.ebi.ac.uk/embl/), respectively. D: Molecular weight in $\mathrm{kDa}$. $x$ indicates that the protein was identified in the according preparation. Proteins listed were identified by LC-MS/MS with a probability score that is significant with $p<0.05$ if the confidence score was $>30$ at a significance threshold for the Mascot result of $p \leq 0.01$.

\section{Abbreviations \\ AK: Adenylate kinase; BNP: Bovine neonatal pancytopenia; BVD(V): Bovine Viral Diarrhoea (virus); CD41: Integrin alpha-IIb; GAPDH: Glyceraldehyde-3- phosphate dehydrogenase; GO terms: Gene ontology project terms; Hsc70: Heat shock cognate 70 kDa protein 8; LC-MS/MS: Liquid- chromatography mass spectrometry/mass spectrometry; MHC I: Major histocompatibility complex class I; MDBK: Madin-darby bovine kidney; (m) M: (milli)Molar; min: Minutes; SDS-PAGE: Sodium dodecyl sulfate polyacrylamide gel electrophoresis; TGF-ß: Transforming growth factor $B$; TRALI: Transfusion-related acute lung injury; TSP 1: Thrombospondin-1; VDBP: Vitamin D-binding protein.}

\section{Competing interests}

No conflicts of interest, financial or otherwise, are declared by the authors.

\section{Authors' contributions}

KN performed cell surface labelling, analyzed the results and wrote the manuscript. SMH carried out mass spectrometry analysis, wrote parts of the manuscript and revised the article. MU contributed to the conception and revision of the article. CAD designed the study, evaluated the results and drafted the article. All authors read and approved the final manuscript.

\section{Acknowledgements}

This work was in part financially supported by the German Federal Office for Agriculture and Food (BLE), grant 2810HSO14 (Deeg).

The authors wish to thank Margarete Swadzba and Roxane Degroote for critical discussions.

\section{Author details}

${ }^{1}$ Institute of Animal Physiology, Department of Veterinary Sciences, LMU Munich, Veterinärstr. 13, München D-80539, Germany. ${ }^{2}$ Research Unit for Protein Science, Helmholtz Zentrum München - Germany Research Center for Environmental Health $(\mathrm{GmbH})$, Ingolstädter Landstr. 1, Neuherberg D-85764, Germany. ${ }^{3}$ Centre of Ophthalmology, Institute for Ophthalmic Research, University of Tübingen, Röntgenweg 11, Tübingen D-72076, Germany.

Received: 9 October 2012 Accepted: 16 January 2013

Published: 23 January 2013

\section{References}

1. Pardon B, Stuyven E, Stuyvaert S, Hostens M, Dewulf J, Goddeeris BM, Cox E, Deprez P: Sera from dams of calves with bovine neonatal pancytopenia contain alloimmune antibodies directed against calf leukocytes. Vet Immunol Immunopathol 2011, 141(3-4):293-300.

2. Friedrich A, Buttner M, Rademacher G, Klee W, Weber BK, Muller M, Carlin A, Assad A, Hafner-Marx A, Sauter-Louis CM: Ingestion of colostrum from specific cows induces Bovine Neonatal Pancytopenia (BNP) in some calves. BMC Vet Res 2011, 7:10.

3. Assad A, Amann B, Friedrich A, Deeg CA: Immunophenotyping and characterization of BNP colostra revealed pathogenic alloantibodies of lgG1 subclass with specifity to platelets, granulocytes and monocytes of all maturation stages. Vet Immunol Immunopathol 2012, 147(1-2):25-34.

4. Foucras G, Corbiere F, Tasca C, Pichereaux C, Caubet C, Trumel C, Lacroux C, Franchi C, Burlet-Schiltz O, Schelcher F: Alloantibodies against MHC class I: a novel mechanism of neonatal pancytopenia linked to vaccination. J Immunol 2011, 187(12):6564-6570.

5. Deutskens F, Lamp B, Riedel CM, Wentz E, Lochnit G, Doll K, Thiel HJ Rumenapf T: Vaccine-induced antibodies linked to bovine neonatal pancytopenia (BNP) recognize cattle major histocompatibility complex class I (MHC I). Vet Res 2011, 42(1):97.

6. Laming E, Melzi E, Scholes SF, Connelly M, Bell CR, Ballingall KT, Dagleish MP, Rocchi MS, Willoughby K: Demonstration of early functional compromise of bone marrow derived hematopoietic progenitor cells during bovine neonatal pancytopenia through in vitro culture of bone marrow biopsies. BMC Res Notes 2012, 5(1):599.

7. Lambton SL, Colloff AD, Smith RP, Caldow GL, Scholes SF, Willoughby K, Howie F, Ellis-Iversen J, David G, Cook AJ, et al: Factors associated with bovine neonatal pancytopenia (BNP) in calves: a case-control study. PLoS One 2012, 7(5):e34183.

8. Sauter-Louis C, Carlin A, Friedrich A, Assad A, Reichmann F, Rademacher G, Heuer C, Klee W: Case control study to investigate risk factors for bovine neonatal pancytopenia (BNP) in young calves in southern Germany. Prev Vet Med 2012, 105(1-2):49-58.

9. Bastian M, Holsteg M, Hanke-Robinson H, Duchow K, Cussler K: Bovine Neonatal Pancytopenia: is this alloimmune syndrome caused by vaccineinduced alloreactive antibodies? Vaccine 2011, 29(32):5267-5275.

10. Madin SH, Darby NB Jr: Established kidney cell lines of normal adult bovine and ovine origin. Proceedings of the Society for Experimental Biology and Medicine Society for Experimental Biology and Medicine 1958, 98(3):574-576.

11. Conceicao MM, Tonso A, Freitas CB, Pereira CA: Viral antigen production in cell cultures on microcarriers Bovine parainfluenza 3 virus and MDBK cells. Vaccine 2007, 25(45):7785-7795.

12. Hwang SR, Steineckert B, Toneff T, Bundey R, Logvinova AV, Goldsmith P, Hook VY: The novel serpin endopin 2 demonstrates cross-class inhibition of papain and elastase: localization of endopin 2 to regulated secretory vesicles of neuroendocrine chromaffin cells. Biochemistry 2002, 41(33):10397-10405.

13. Cirri E, Katz A, Mishra NK, Belogus T, Lifshitz Y, Garty H, Karlish SJ, Apell HJ: Phospholemman (FXYD1) raises the affinity of the human alpha1beta1 isoform of $\mathrm{Na}$, K-ATPase for $\mathrm{Na}$ ions. Biochemistry 2011, 50(18):3736-3748.

14. Babiuk S, Horseman B, Zhang C, Bickis M, Kusalik A, Schook LB, Abrahamsen MS, Pontarollo R: BoLA class I allele diversity and polymorphism in a herd of cattle. Immunogenetics 2007, 59(2):167-176.

15. Hezmee MN, Shiels IA, Rolfe BE, Mills PC: Complement C5a: impact on the field of veterinary medicine. Vet J 2012, 192(3):264-271.

16. Heiss A, DuChesne A, Denecke B, Grotzinger J, Yamamoto K, Renne T, Jahnen-Dechent W: Structural basis of calcification inhibition by alpha 2- 
HS glycoprotein/fetuin-A. Formation of colloidal calciprotein particles. J Biol Chem 2003, 278(15):13333-13341.

17. Chun RF, Peercy BE, Adams JS, Hewison M: Vitamin D binding protein and monocyte response to 25 -hydroxyvitamin $D$ and 1,25-dihydroxyvitamin D: analysis by mathematical modeling. PLoS One 2012, 7(1):e30773.

18. Tolosano E, Fagoonee S, Morello N, Vinchi F, Fiorito V: Heme scavenging and the other facets of hemopexin. Antioxid Redox Signal 2010, 12(2):305-320

19. Rahman MM, Miranda-Ribera A, Lecchi C, Bronzo V, Sartorelli P, Franciosi F, Ceciliani F: Alpha(1)-acid glycoprotein is contained in bovine neutrophil granules and released after activation. Vet Immunol Immunopathol 2008, 125(1-2):71-81.

20. Congote LF, Temmel N, Sadvakassova G, Dobocan MC: Comparison of the effects of serpin A1, a recombinant serpin A1-IGF chimera and serpin A1 C-terminal peptide on wound healing. Peptides 2008, 29(1):39-46.

21. Takagi J, Fujisawa T, Usui T, Aoyama T, Saito Y: A single chain 19-kDa fragment from bovine thrombospondin binds to type $V$ collagen and heparin. J Biol Chem 1993, 268(21):15544-15549.

22. Vipond C, Suker J, Jones C, Tang C, Feavers IM, Wheeler JX: Proteomic analysis of a meningococcal outer membrane vesicle vaccine prepared from the group B strain NZ98/254. Proteomics 2006, 6(11):3400-3413.

23. Chi SL, Pizzo SV: Cell surface F1Fo ATP synthase: a new paradigm? Ann Med 2006, 38(6):429-438.

24. Noe W, Bux R, Berthold W, Werz W: Optimization of vaccine production for animal health. Cytotechnology 1994, 15(1-3):169-176.

25. Hsieh CJ, Kim TW, Hung CF, Juang J, Moniz M, Boyd DA, He L, Chen PJ, Chen $\mathrm{CH}$, Wu TC: Enhancement of vaccinia vaccine potency by linkage of tumor antigen gene to gene encoding calreticulin. Vaccine 2004, 22(29-30):3993-4001.

26. Lovgren $\mathrm{K}$, Morein B: The requirement of lipids for the formation of immunostimulating complexes (iscoms). Biotechnol Appl Biochem 1988, 10(2):161-172.

27. Sun HX, Xie Y, Ye YP: Advances in saponin-based adjuvants. Vaccine 2009, 27(12):1787-1796

28. Skene $C D$, Sutton P: Saponin-adjuvanted particulate vaccines for clinical use. Methods 2006, 40(1):53-59.

29. Gupta RK, Relyveld EH, Lindblad EB, Bizzini B, Ben-Efraim S, Gupta CK: Adjuvants-a balance between toxicity and adjuvanticity. Vaccine 1993, 11(3):293-306

30. Clifton JG, Huang F, Kovac S, Yang X, Hixson DC, Josic D: Proteomic characterization of plasma-derived clotting factor VIII-von Willebrand factor concentrates. Electrophoresis 2009, 30(20):3636-3646.

31. Kihara H, Ohno N, Karakawa S, Mizoguchi Y, Fukuhara R, Hayashidani M, Nomura S, Nakamura K, Kobayashi M: Significance of immature platelet fraction and CD41-positive cells at birth in early onset neonatal thrombocytopenia. Int J Hematol 2010, 91(2):245-251.

32. Nicholls C, Li H, Liu JP: GAPDH: A common enzyme with uncommon functions. Clin Exp Pharmacol Physiol 2012, 39(8):674-679.

33. Greinacher A, Wesche J, Hammer E, Furll B, Volker U, Reil A, Bux J: Characterization of the human neutrophil alloantigen-3a. Nat Med 2010, 16(1):45-48.

34. Reil A, Keller-Stanislawski B, Günay S, Bux J: Specificities of leucocyte alloantibodies in transfusion-related acute lung injury and results of leucocyte antibody screening of blood donors. Vox Sang 2008, 95(4):313-317.

35. Lopez-Alemany $\mathrm{R}$, Longstaff $\mathrm{C}$, Hawley $\mathrm{S}$, Mirshahi $\mathrm{M}$, Fabregas $\mathrm{P}$, Jardi $\mathrm{M}$, Merton E, Miles LA, Felez J: Inhibition of cell surface mediated plasminogen activation by a monoclonal antibody against alphaEnolase. Am J Hematol 2003, 72(4):234-242.

36. Saulot V, Vittecoq O, Charlionet R, Fardellone P, Lange C, Marvin L, Machour $N$, Le Loet $X$, Gilbert D, Tron F: Presence of autoantibodies to the glycolytic enzyme alpha-enolase in sera from patients with early rheumatoid arthritis. Arthritis Rheum 2002, 46(5):1196-1201.

37. Lee JH, Cho SB, Bang D, Oh SH, Ahn KJ, Kim J, Park YB, Lee SK, Lee KH: Human anti-alpha-enolase antibody in sera from patients with Behcet's disease and rheumatologic disorders. Clin Exp Rheumatol 2009, 27(2 Suppl 53):S63-S66.

38. Leung SM, Senisterra G, Ritchie KP, Sadis SE, Lepock JR, Hightower LE: Thermal activation of the bovine Hsc70 molecular chaperone at physiological temperatures: physical evidence of a molecular thermometer. Cell Stress Chaperones 1996, 1(1):78-89.
39. Munakata S, Chen M, Aosai F, Kawaguchi N, Nemoto Y, Norose $K$, Hattori T, Yano A: The clinical significance of anti-heat shock cognate protein 71 antibody in myasthenia gravis. J Clin Neurosci 2008, 15(2):158-165.

40. Alard JE, Hillion S, Guillevin L, Saraux A, Pers JO, Youinou P, Jamin C: Autoantibodies to endothelial cell surface ATP synthase, the endogenous receptor for hsp60, might play a pathogenic role in vasculatides. PLoS One 2011, 6(2):e14654.

41. Huber-Lang M, Sarma JV, Zetoune FS, Rittirsch D, Neff TA, McGuire SR, Lambris JD, Warner RL, Flierl MA, Hoesel LM, et al: Generation of C5a in the absence of C3: a new complement activation pathway. Nat Med 2006, 12(6):682-687

42. Boteva L, Morris DL, Cortes-Hernandez J, Martin J, Vyse TJ, Fernando MM: Genetically determined partial complement C4 deficiency states are not independent risk factors for SLE in UK and Spanish populations. Am J Hum Genet 2012, 90(3):445-456.

43. White $\mathrm{P}, \mathrm{Cooke} \mathrm{N}$ : The multifunctional properties and characteristics of vitamin D-binding protein. Trends Endocrinol Metab 2000, 11(8):320-327.

44. Lopez-Dee Z, Pidcock K, Gutierrez LS: Thrombospondin-1: multiple paths to inflammation. Mediators Inflamm 2011, 2011:296069.

45. van Pel M, van Os R, Velders GA, Hagoort H, Heegaard PM, Lindley IJ, Willemze R, Fibbe WE: Serpina1 is a potent inhibitor of IL-8-induced hematopoietic stem cell mobilization. Proc Natl Acad Sci USA 2006, 103(5):1469-1474.

46. Mangan MS, Kaiserman D, Bird PI: The role of serpins in vertebrate immunity. Tissue Antigens 2008, 72(1):1-10.

47. Ledoux-Corbusier M, Achten G: alpha1-Antitrypsin deficiency and skin abnormalities. J Cutan Pathol 1975, 2(1):25-29.

48. Pannicke U, Honig M, Hess I, Friesen C, Holzmann K, Rump EM, Barth TF, Rojewski MT, Schulz A, Boehm T, et al: Reticular dysgenesis (aleukocytosis) is caused by mutations in the gene encoding mitochondrial adenylate kinase 2. Nat Genet 2009, 41(1):101-105.

49. Emile JF, Geissmann F, Martin OC, Radford-Weiss I, Lepelletier Y, Heymer B, Espanol T, de Santes KB, Bertrand Y, Brousse N, et al: Langerhans cell deficiency in reticular dysgenesis. Blood 2000, 96(1):58-62.

50. Lemberger SIK, Dorsch R, Hauck SM, Amann B, Hirmer S, Hartmann K, Deeg CA: Decrease of Trefoil factor 2 in cats with feline idiopathic cystitis. BJU Int 2011, 107(4):670-677.

51. Hauck SM, Dietter J, Kramer RL, Hofmaier F, Zipplies JK, Amann B, Feuchtinger A, Deeg CA, Ueffing M: Deciphering membrane-associated molecular processes in target tissue of autoimmune uveitis by label-free quantitative mass spectrometry. Mol Cell Proteomics 2010, 9(10):2292-2305.

52. Hauck SM, Hofmaier F, Dietter J, Swadzba ME, Blindert M, Amann B, Behler J, Kremmer E, Ueffing M, Deeg CA: Label-free LC-MSMS analysis of vitreous from autoimmune uveitis reveals a significant decrease in secreted Wnt signalling inhibitors DKK3 and SFRP2. J Proteomics 2012, 75(14):4545-4554.

doi:10.1186/1746-6148-9-18

Cite this article as: Euler et al:: Bovine neonatal pancytopenia -

Comparative proteomic characterization of two BVD vaccines and the producer cell surface proteome (MDBK). BMC Veterinary Research 2013 9:18

\section{Submit your next manuscript to BioMed Central and take full advantage of:}

- Convenient online submission

- Thorough peer review

- No space constraints or color figure charges

- Immediate publication on acceptance

- Inclusion in PubMed, CAS, Scopus and Google Scholar

- Research which is freely available for redistribution 